\title{
Zeldzame ziekten: een onmogelijke diagnostische opgave?
}

\section{ZELDZAME ZIEKTEN NADER BEKEKEN}

Zeldzame ziekten zijn ziekten die per definitie een prevalentie hebben van minder dan 0,5 per 1000 inwoners. ${ }^{1-4}$ De gemiddelde huisarts ziet in zijn hele carrière dan ook maar 1-2 keer een patiënt met die ene specifieke zeldzame aandoening. Toch ziet $\mathrm{u}$ vaker een patiënt met een zeldzame aandoening dan u denkt, want er zijn bijna 800 zeldzame aandoeningen, dus in een normpraktijk zullen 100-150 patiënten een zeldzame ziekte hebben. In totaal hebben naar schatting een miljoen Nederlanders een zeldzame ziekte, bijna even veel als er diabetespatiënten zijn [figuur].5,6 Vier op de vijf zeldzame aandoeningen hebben een erfelijke component.

De meeste zeldzame ziekten zijn complexe, levensbedreigende of chronisch invaliderende aandoeningen. ${ }^{4}$ Wie aan een zeldzame ziekte denkt, denkt wellicht aan een onbekend ziektebeeld waarvan de symptomen niet tot de parate kennis behoren. Toch is dit niet per se het geval: sommige zeldzame aandoeningen zijn bepaald niet onbekend. In het [kader] staan er een aantal op volgorde van prevalentie.

De diagnose 'pre-eclampsie, 'uveïtis' of 'ziekte van Ménière' zal meestal geen probleem zijn voor de huisarts, maar bij het noonansyndroom (zie [kader] op www.henw.org, rubriek Nascholing), neurofibromatose type 1, cushingsyndroom of osteogenesis imperfecta duurt het vaak langer voordat de juiste diagnose gevonden is. Veel zeldzame ziekten ontwikkelen

\begin{abstract}
Samenvatting
Hendriks SA, Sollie JW, Nijnuis MG, Stolper CF. Zeldzame ziekten: een onmogelijke diagnostische opgave? Huisarts Wet 2016;59(11):498-501.

Zeldzame aandoeningen zijn aandoeningen met een prevalentie van minder dan 0,5 per 1000 mensen; er zijn er bijna 8000 bekend. Het is voor een huisarts onmogelijk al deze aandoeningen zelfs maar bij benadering te kennen, maar dat is ook niet nodig. Belangrijker is het dat de huisarts tijdig aan het denken wordt gezet en getriggerd wordt tot nader onderzoek of verwijzing. De huisarts beschikt over prima diagnostische gereedschappen: 'awareness', het 'plusteken' (een opvallende combinatie van symptomen), het pluis/niet-pluisgevoel, de familieanamnese en goed luisteren naar de patiënt. Online is voldoende betrouwbare informatie te vinden om bij een vermoeden verwijzing naar de tweede of derde lijn te ondersteunen. Met tijdige diagnostiek is veel gezondheidswinst te behalen. Juist omdat genezing vaak niet mogelijk is, is de patiënt gebaat bij passende symptomatische behandeling en goede toegang tot voorzieningen. Meer nascholing op dit gebied is nodig. Het kan een uitdaging voor huisartsen zijn om dit stuk diagnostiek tot hun taak te gaan rekenen.
\end{abstract}

Vereniging van Samenwerkende Ouder- en Patiëntenorganisaties (VSOP), Koninginnelaan 233762 DA Soest: S.A. Hendriks, arts en beleidsmedewerker Zorg; M.G. Nijnuis, arts en beleidsmedewerker Zorg. VU medisch centrum, Afdeling Huisartsgeneeskunde \& ouderengeneeskunde: J.W. Sollie, huisarts-onderzoeker. Universiteit Maastricht, afdeling Huisartsgeneeskunde en Universiteit Antwerpen, afdeling Huisartsgeneeskunde: dr. C.F. Stolper, huisarts-onderzoeker • Correspondentie: s.hendriks@vsop.nl•Mogelijke belangenverstrengeling: niets aangegeven.

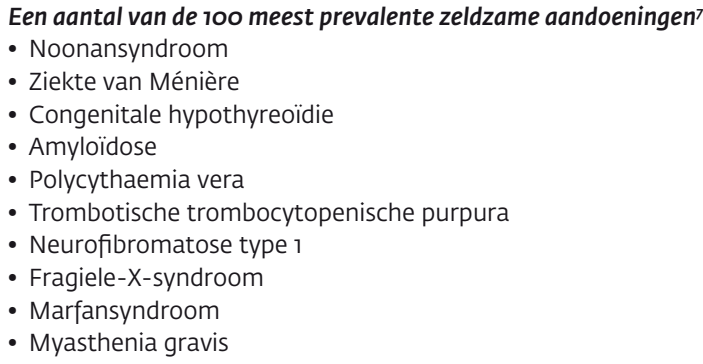

- Ziekte van Ménière

- Congenitale hypothyreoïdie

- Amyloïdose

- Polycythaemia vera

- Trombotische trombocytopenische purpura

- Neurofibromatose type 1

- Fragiele-X-syndroom

- Marfansyndroom

- Myasthenia gravis

zich langzaam, met vooral vage en aspecifieke symptomen. Bij volwassenen ziet men bijvoorbeeld vermoeidheid, hoofdpijn en algemene malaise; bij kinderen een afwijkende groeicurve of een trage ontwikkeling. Meestal levert een eerste oriënterend onderzoek niets specifieks op en het gevaar bestaat dat het diagnostische spoor daarna doodloopt op alternatieve verklaringen zoals spanningsklachten of burn-out.

Gemiddeld wordt de diagnose bij een zeldzame ziekte pas zeven jaar na het begin van de klachten gesteld. ${ }^{10}$ Dat stemt tot nadenken. Er zijn naar schatting 400 diagnoses die het bureau van de huisarts minstens eenmaal per jaar passeren, ${ }^{11}$ en er zijn daarnaast heel veel diagnoses die maar eens in de paar jaar voorbijkomen. Wat kan de huisarts betekenen voor die zeldzamere ziekten? Over welk gereedschap beschikt de huisarts om dit diagnostische traject te versnellen? Kan de patiënt zelf ook bijdragen aan de diagnostiek? Wat heeft de patiënt er aan dat de diagnose eerder gesteld wordt terwijl de therapeutische mogelijkheden waarschijnlijk beperkt zijn?

In dit artikel zetten we de diagnostische mogelijkheden op een rij en wijzen we op een aantal bruikbare en betrouwbare online bronnen voor de huisarts die op zoek is naar een mogelijke zeldzame ziekte.

\section{De kern}

- Elke huisartsenpraktijk heeft een aanzienlijk aantal patiënten met een zeldzame ziekte: in een normpraktijk zijn er ongeveer 100-150.

- 'Awareness', het 'plusteken', het pluis/niet-pluisgevoel, de familieanamnese en goed luisteren zijn uitstekende diagnostische hulpmiddelen om het vermoeden van een zeldzame ziekte te ontwikkelen.

- Met behulp van specifieke internetzoekmachines kan een huisarts zich een idee vormen van mogelijke zeldzame ziektes.

- Door in de verwijsbrief expliciet de mogelijkheid van een zeldzame ziekte te noemen, wordt de kans op het vinden ervan verhoogd.

- Het kan voor huisartsen een uitdaging zijn de opsporing van zeldzame ziekten tot hun takenpakket te gaan rekenen; daarnaast is nascholing op dit gebied nodig. 


\section{WAT LEVERT TIJDIGE DIAGNOSE OP?}

Een enquête onder 12.00o Europeanen met een zeldzame ziekte liet zien dat circa $37 \%$ van de ondervraagden aanvankelijk een verkeerde diagnose kreeg en $52 \%$ een onjuiste behandeling ontving; $56 \%$ gaf aan nadelen te ondervinden van het diagnostisch delay. Vaak was er overdiagnostiek; 13\% van de patiënten consulteerde meer dan vijf artsen voordat de correcte diagnose werd gevonden. ${ }^{10}$

Tijdige diagnose kan voor de patiënt van groot belang zijn. Amyloïdose leidt onbehandeld tot een vroege dood, ${ }^{12}$ een nietherkende osteogenesis imperfecta leidt al snel tot vermoedens van kindermishandeling ${ }^{13,14}$ en het familiair voorkomende lange-QT-syndroom kan levensbedreigend flauwvallen veroorzaken bij jonge kinderen. ${ }^{15,16}$ Urethrakleppen kunnen ernstige nierinsufficiëntie veroorzaken; ${ }^{17}$ het missen van een addisoncrisis bij bijnierinsufficiëntie kan fatale gevolgen hebben. ${ }^{18}$ Het cushingsyndroom leidt onbehandeld tot een fors postuur, gedragsveranderingen en vaak extreme moeheid. De hoge cortisolspiegel is schadelijk voor bloedvaten, hart, spieren, botten en hersenen en brengt bovendien andere hormoonsystemen uit balans. ${ }^{18}$ En bij vroegtijdige herkenning van een mentaal retardatiesyndroom bij een kind, zoals het fragiele-X syndroom, kan aan kind en gezin de juiste ondersteuning geboden worden. ${ }^{19}$

Het uitblijven van de juiste diagnose zorgt voor onzekerheid en frustratie bij patiënten, voor onbegrip bij de omgeving en voor problemen met instanties. Zonder diagnose is vaak geen begeleiding te krijgen (thuis, op school of op het werk) en komt men niet in aanmerking voor voorzieningen en vergoedingen. Het platform Ziekte Onbekend ondersteunt ouders van chronisch zieke kinderen zonder diagnose of met een ultrazeldzame aandoening (www.ziekteonbekend.nl). ${ }^{18}$

Voor veel zeldzame ziekten bestaat geen curatieve behandeling, maar adequate begeleiding en symptoombestrijding maakt het leven ook voor deze patiënten draaglijker. Bovendien kan het vaststellen van een erfelijke ziekte gevolgen hebben voor een preconceptioneel advies.

\section{Iris}

Iris, 39 jaar, haalt op het spreekuur een verwijzing naar de diëtiste. Zij worstelt al jaren met haar gewicht maar deze keer lukt het haar niet om af te vallen. Het vet zit vooral rond haar buik. De huisarts ziet dat zij eerder dat jaar geïnformeerd heeft naar een ooglidcorrectie in verband met hangende oogleden. Er was onvoldoende indicatie voor die ingreep.

Een jaar later meldt zij zich opnieuw: ook met hulp van de diëtiste lukt het niet om af te vallen. Iris heeft gelezen over het syndroom van Cushing en zij vraagt de huisarts daar onderzoek naar te doen. De huisarts doet een eenmalige cortisolmeting; de waarde valt binnen de norm (hoognormaal).

Een half jaar later komt Iris op het spreekuur met vage sensibiliteitsstoornissen in het gelaat, moeheid, moeite met fietsen en hoofdpijn. De huisarts verwijst haar naar de neuroloog; deze laat een MRI-cerebrum maken. Uitslag: afwijkingen niet passend bij de leeftijd. De neuroloog meet een verhoogde bloeddruk, maar meldt dit niet aan patiënte. Aanvullend neurologisch onderzoek sluit oorzaken zoals de ziekte van Lyme en multipele sclerose uit. Na zes maanden wordt opnieuw een MRI-cerebrum gemaakt, maar daarop zijn geen nieuwe afwijkingen te zien.
Figuur Geschatte cumulatieve prevalentie van zeldzame ziekten in Nederland, op basis van de beschikbare gegevens van $\mathbf{5 6 2}$ zeldzame ziekten (in totaal zijn er ongeveer 8000 zeldzame ziekten) ${ }^{5}$

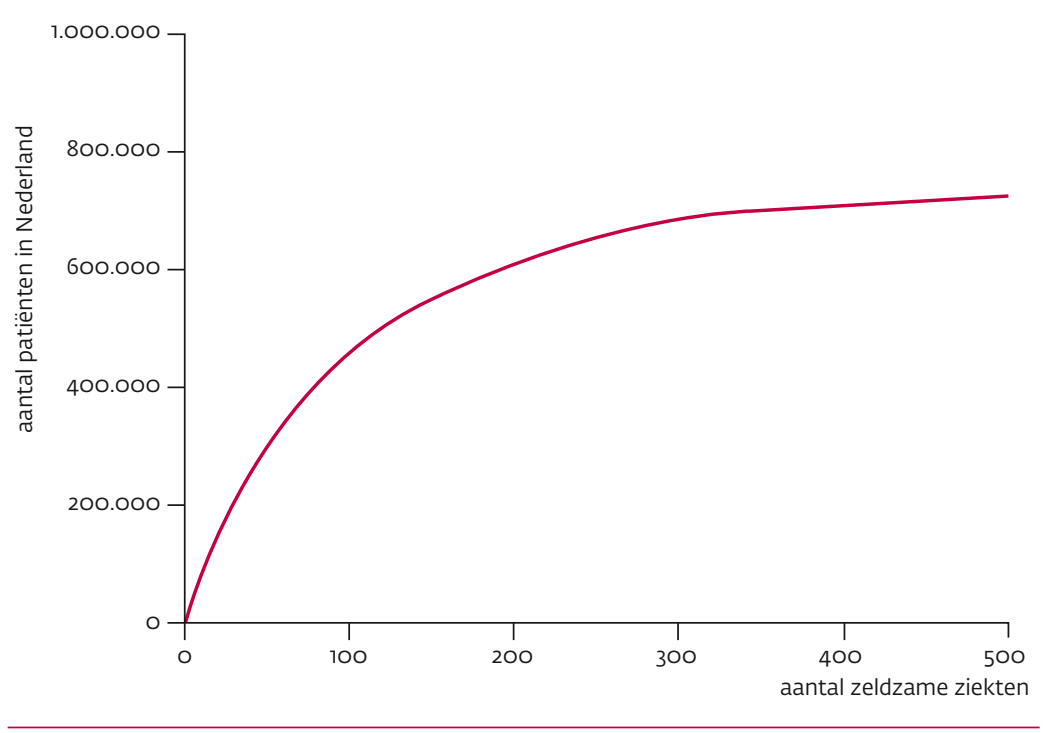

HET DIAGNOSTISCH ARSENAAL VAN DE HUISARTS

Huisartsen kunnen het diagnostische traject versnellen, niet zozeer door zelf de juiste diagnose te stellen maar wel doordat zij de eersten zijn die op het idee kunnen komen dat er mogelijk een zeldzame ziekte in het spel is. Welke diagnostische gereedschappen staan de huisarts daarvoor ter beschikking? ${ }^{20,21}$

\section{Awareness}

'Je gaat het pas zien als je het doorhebt' is een uitspraak die ook geldt voor de herkenning van een zeldzame ziekte. Als een huisarts zich ervan bewust is dat zeldzame aandoeningen als groep een vrij grote prevalentie hebben, zal die mogelijkheid sneller in de differentiaaldiagnose terechtkomen. Gerichte nascholing kan helpen deze bewustwording te vergroten. ${ }^{21}$

\footnotetext{
Abstract

Hendriks SA, Sollie JW, Nijnuis MG, Stolper CF. Rare diseases: an impossible diagnostic challenge? Huisarts Wet 2016;59(17):498-501.

Rare diseases are those with a prevalence of less than 1 in 2000 and about 8000 have been identified. While it is impossible for general practitioners (GPS) to be able to diagnose all these diseases, it is important that they are alert to possible diagnoses and order investigations or refer the patient on as soon as possible. GPs have excellent diagnostic tools - awareness, recognition of an unusual combination of signs, 'gut feelings', knowledge of the family history, and ability to listen to the patient. The availability of reliable online resources can back up suspicions and contribute to a timely referral to secondary or tertiary care. Limiting the diagnostic delay is important, especially because cure is often not possible and patients can benefit from appropriate symptomatic treatment and access to facilities and services. Even if the exact diagnosis is not established, patients benefit from the support and supervision provided by their GP.
} 
Intussen heeft Iris zich verdiept in het syndroom van Cushing. Ze herkent de progressieve proximale spierzwakte en blauwe plekken die daarbij kunnen voorkomen. Ze dringt bij haar huisarts aan op een verwijzing naar de internist, die een dexamethasonremmingstest uitvoert. De uitslag wijst op overproductie van cortisol vanuit de bijnier, en op de CT-scan is een eenzijdige tumor van de bijnier te zien. Patiënte wordt verwezen naar een expertisecentrum voor bijnierziekten, waar wordt besloten tot laparoscopische bijnierextirpatie. Door vertraging in de interdisciplinaire overdracht (vakantie, diensten), operatiewachttijden en patiëntfactoren verstrijken er nog eens zes maanden tussen de diagnose en de ingreep.

Anderhalf jaar na de ingreep is Iris 43,5 jaar. $\mathrm{Na}$ een periode van invaliderende bijnierinsufficiëntie door onvoldoende werking van de resterende bijnier is haar bijnierfunctie volledig hersteld. Ze is zonder dieet $20 \mathrm{~kg}$ afgevallen en haar gelaat en postuur hebben weer normale contouren. De spierkracht en algehele conditie nemen toe. De bloeddruk is zonder medicatie normaal. Achteraf bleken de afwijkingen op de MRI mogelijk toch gerelateerd aan de verhoogde cortisolspiegels.

Iris blijft onder controle in verband met een verhoogd risico op type-2-diabetes en hypertensie. De specialist in het expertisecentrum meldt de huisarts dat een eenmalige cortisolbepaling in het bloed onvoldoende is voor het aantonen of uitsluiten van de diagnose 'cushingsyndroom'.

\section{Afwijkende patronen, het 'plusteken'}

Huisartsen zijn gewend afwijkende patronen van symptomen en onderzoeksbevindingen op te merken. Zij zijn minder geneigd om in orgaansystemen te denken en meer om op het geheel van de klachten te letten. Zij kennen de context: de voorgeschiedenis, de familieanamnese en de kenmerken van de patiënt zelf. Huisartsen denken in proporties: een klacht of een symptoom kan buitenproportioneel zijn voor het patroon van een gewone ziekte of voor wat gebruikelijk is bij die ene patiënt. In de literatuur wordt ook het 'plusteken' genoemd, de combinatie van een gewone ziekte en een niet-bijpassend symptoom..$^{22}$ Als een patiënt diabetes heeft en ook nog doof is, kan dat wijzen op een mitochondriale stofwisselingsziekte. Onverklaarde hyponatriëmie bij een patiënt met chronische buikpijn kan duiden op een stoornis in de haemsynthese zoals bij acute intermitterende porfyrie.

\section{Pluis/niet-pluisgevoel}

Ook zonder harde aanwijzingen voor een ziekte kan een huisarts denken: 'Er klopt iets niet bij deze patiënt'. Het pluis/ niet-pluisgevoel is een vorm van skilled intuition die de huisarts rechtop in zijn stoel zet, op zoek naar de nog verborgen alerting triggers. ${ }^{23,24}$ Het leidt tot het genereren van diagnostische werkhypotheses, waarin soms een zeldzame ziekte past. Ook als ouders intuïtief voelen dat hun kind 'anders is dan anders', of zich anders gedraagt dan andere kinderen, kan dat het pluis/ niet-pluisgevoel activeren. ${ }^{25}$

\section{Familieanamnese}

Vier op de vijf zeldzame ziekten hebben een erfelijke component, daarom is een goede familieanamnese onontbeerlijk in het diagnostische traject, al sluit een negatieve familieanamnese een erfelijke component niet uit. Het evalueren van de bevindingen kan zo nodig gebeuren in overleg met een kli- nisch geneticus, bijvoorbeeld een die verbonden is aan een expertisecentrum op het terrein van de (vermoedelijke) aandoening (zie [kader Expertisecentra]).

\section{Expertisecentra}

In 2015 is de Nederlandse Federatie van Universitaire medische centra (NFU) in opdracht van het ministerie van VWS begonnen met het aanwijzen van expertisecentra. Deze centra bundelen kennis over en ervaring met een bepaalde aandoening of cluster van aandoeningen, ontwikkelen protocollen en richtlijnen, coördineren onderzoek en zorgen voor adequate verwijzing van patiënten binnen en buiten Nederland. Ook geven ze patiënten en behandelaars adviezen over doeltreffende zorg.

Inmiddels zijn er in Nederland ruim 300 erkende expertisecentra. Lijsten ervan zijn te downloaden via diverse websites, waaronder die van de NFU (www.nfu.nl/patientenzorg/complexezorg/ zeldzame-ziekten). ${ }^{26}$ Op Europees niveau wordt gewerkt aan het opzetten van internationale expertisenetwerken. ${ }^{27}$

Huisartsen kunnen bij deze centra terecht voor consultatie wanneer zij een bepaalde zeldzame aandoening vermoeden, en voor vragen en advies nadat de diagnose gesteld is.

\section{Zoekmachine}

Het internet bevat ruim anderhalf miljard medische artikelen. Naast algemene zoekmachines zoals Google Scholar en databases zoals PubMed zijn er ook symptomen-tools zoals Findzebra (www.findzebra.com) en Phenomizer (compbio. charite.de/phenomizer), die de huisarts sneller op het spoor zetten van zeldzame aandoeningen. ${ }^{28}$

\section{GEZAMENLIJK DIAGNOSTISCH TRAJECT}

In hoeverre de gut feeling van een patiënt de huisarts helpt bij het stellen van een diagnose is nog maar weinig onderzocht. Goed luisteren naar wat de patiënt vertelt over diens lichaam zal zeker bijdragen aan het diagnostisch redeneren. Patiënten hebben vaak zelf al op internet gezocht en ideeën verzameld; soms zitten daar heel goede suggesties bij. ${ }^{29}$ Maar artsen selecteren symptomen op basis van hun kennis en negeren soms te makkelijk symptomen die niet bij die kennis passen. Wanneer die kennis in de arts-patiëntrelatie ontaardt in macht, kan relevante informatie onder de radar blijven.

De zoektocht naar een zeldzame aandoening duurt meestal lang en vraagt uithoudingsvermogen - van de patiënt, maar ook van de huisarts. Als een huisarts de mogelijkheid van een zeldzame ziekte serieus overweegt, helpt het om van tevoren met de patiënt te bespreken dat het een gezamenlijke zoektocht is en dat het lang kan duren voor er duidelijkheid is. Na elke diagnostische stap moeten huisarts en patiënt samen besluiten hoe ze verdergaan.

\section{Verwijzen}

De juiste diagnose wordt meestal gesteld in een tweede- of derdelijns instelling. Huisartsen kunnen de kans op de juiste diagnose verhogen door in hun verwijsbrief uitdrukkelijk te melden dat ze een zeldzame ziekte vermoeden. Niet alle specialisten zijn thuis op dat gebied.

Kinderen kunnen het beste verwezen worden naar een 
algemeen kinderarts in een UMC. In UMC's en topklinische ziekenhuizen zijn ook kinderartsen Erfelijke en Aangeboren Aandoeningen (EAA) werkzaam.

Volwassenen met een opvallende familieanamnese zijn het meest gebaat bij een verwijzing naar een klinisch geneticus (zie www.vkgn.org/index.php/voorlichting/poliklinieken-klinische-genetica).

Derdelijnszorg vindt plaats in universitaire centra en topklinische ziekenhuizen en in deze instellingen bevinden zich expertisecentra. Op www.zichtopzeldzaam.nl staan de erkende expertisecentra (zie [kader]) vermeld als ook de verschillende relevante patiëntenorganisaties en diverse publicaties over zeldzame ziektes voor professionals en patiënten.

\section{Hoe verder na een antwoord uit de tweede lijn?}

Als een verwijzing de juiste diagnose oplevert, kunnen patiënten en professionals gericht op zoek naar informatie en eventuele richtlijnen of zorgstandaarden. Maar niet altijd levert een verwijzing een diagnose op. 'Op mijn terrein zijn geen afwijkingen gevonden', staat er dan in de brief van de specialist. Huisartsen hebben bij uitstek een holistische blik en kunnen tunnelvisie voorkomen. Als de huisarts toch een sterk vermoeden houdt, kan hij een expertisecentrum om een second opinion vragen of een andere diagnostische weg inslaan.

Van de 700 kinderen die in Nederland ieder jaar geboren worden met een ontwikkelingsachterstand, blijft ook met alle nieuwe genetische technieken $30-50 \%$ zonder diagnose. Vaak hebben deze kinderen veel problemen: voedingsproblemen, failure to thrive, epilepsie, spasticiteit of juist hypotonie. Het is van groot belang dat ouders en kind wel de juiste ondersteuning krijgen voor thuis en op school.

\section{KENNISBRONNEN}

\section{Nascholing}

In oktober 2013 is het Nationaal Plan Zeldzame Ziekten (NPZZ) overhandigd aan minister Schippers van Volksgezondheid, Welzijn en Sport. Het plan bevat de aanbeveling om awareness en de kennis van zeldzame ziekten bij huisartsen en jeugdartsen te verbeteren. Huisartsen hebben duidelijk de behoefte kenbaar gemaakt aan nascholing op het gebied van genetica en zeldzame aandoeningen, ${ }^{30,31}$ maar er is nog betrekkelijk weinig ontwikkeld. Wel is er de website www.huisartsengenetica.nl voor vragen over erfelijkheid en is onderwijs (e-learning) in ontwikkeling.

\section{Online bronnen}

De Vereniging Samenwerkende Patiënten en Ouderorganisaties (VSOP, www.vsop.nl) overkoepelt circa 70 patiëntenorganisaties op het gebied van aandoeningen met een zeldzaam, erfelijk of aangeboren karakter en behartigt de belangen van mensen met een zeldzame aandoening bij zowel politieke instellingen als in het brede zorgveld. Op YouTube heeft de VSOP een eigen kanaal met informatieve filmpjes met patiëntenverhalen over hemofilie, het cushingsyndroom en neurofibromatose type 1 (www.youtube.com/channel/UCn-

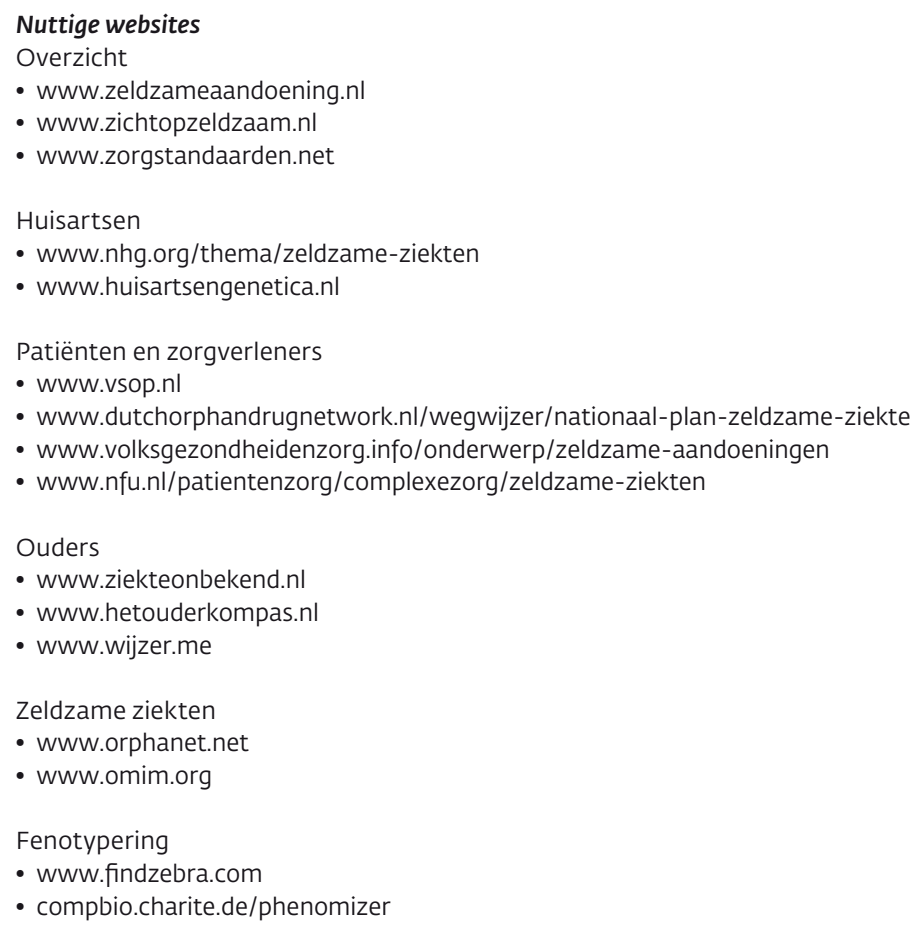

57CrmtOnJu8xARZIZ5RZw).

NHG, VSOP en verschillende patiëntenorganisaties hebben gezamenlijk een brochurereeks over zeldzame aandoeningen gemaakt voor huisartsen (www.nhg.org/thema/zeldzameziekten).

Het [kader] geeft een lijst van goede online bronnen. De website www.zeldzameaandoening.nl is een goede startpagina om wegwijs te raken in het veld van zeldzame ziekten.

\section{CONCLUSIE}

In elke huisartsenpraktijk lopen patiënten rond met een nog niet vastgestelde zeldzame ziekte. De onverklaarde klachten hiervan veroorzaken een behoorlijke ziektelast voor de patiënt en een belasting voor de huisarts. Het duurt nog steeds gemiddeld zeven jaar voor de diagnose gesteld wordt. Huisartsen zijn bij uitstek in staat een eerste vermoeden van een zeldzame ziekte te krijgen. Zij beschikken over bruikbaar instrumentarium om dat vermoeden te ontwikkelen en de patiënt gericht te verwijzen. Er is meer specifieke nascholing op dit gebied nodig, maar het kan een uitdaging voor huisartsen zijn om dit stuk diagnostiek tot hun taak te gaan rekenen.

\section{LITERATUUR}

Zie www.henw.org, rubriek Nascholing. 


\section{Bijlage bij Zeldzame ziekten: een onmogelijke diagnostische opgave?}

\section{Kenmerken van het noonansyndroom ${ }^{8,9}$}

- Autosomaal dominant erfelijke aandoening, behoort tot een groep aandoeningen waarbij het RAS-eiwit in de RAS-MAPK-pathway niet goed functioneert; een voorbeeld is neurofibromatose type 1

- Incidentie: 180 diagnoses per jaar in Nederland

- Variatie in ernst en expressie

- Uiterlijke kenmerken: lage oorstand, buitenooghoeken omlaag gericht (downslanting palpebral fissures), neus met brede basis, korte brede hals

- Kleine gestalte (voor kinderen met noonansyndroom zijn speciale groeidiagrammen beschikbaar vanwege de afwijkende lengtegroei)

- Bijkomende morbiditeit: hartafwijkingen, voedingsproblemen, ontwikkelingsachterstand

- Autismespectrumstoornissen en ADHD komen vaak voor

- Speciaal onderwijs is vaak geïndiceerd, ook bij normale intelligentie

- Alexithymie (onvermogen om gevoelens te onderkennen en te verwoorden): 'het gaat altijd goed'

\section{LITERATUUR}

1 Orphan drugs and rare diseases at a glance. London: European Medicines Agency Press office; 2007.

2 Rare diseases in numbers [factsheet]. Paris: Eurordis/Orphanet; 2005.

3 Nationaal Plan Zeldzame Ziekten. Den Haag: ZonMw; 2013.

4 Aanbeveling van de Raad van 8 juni 2009 betreffende een optreden op het gebied van zeldzame ziekten. Publicatieblad van de Europese Unie 2009/C $151 / 02$.

5 Nugteren R, Siderius EJ, Achterberg PW, Van Breukelen S, Eysink PED. Zeldzame aandoeningen. Volksgezondheid Toekomst Verkenning, Nationaal Kompas Volksgezondheid. Bilthoven: RIVM, versie 4.17, 23 juni 2014.

6 Forum Biotechnologie en Genetica. Signalement 'Vroegere diagnostiek van zeldzame ziekten'. Den Haag: FBG; 2014.

7 Rath A, Nguengang Wakap S. Prevalence and incidence of rare diseases: Bibliographic data. Orphanet Report Series, Rare Diseases collection, number 2. Paris; Orphanet; 2016.

8 Hendriks S. Informatie voor de huisarts over noonansyndroom. Soest/ Utrecht: VSOP/NHG/Stichting Noonan Syndroom; 2016.

9 Bhambhani V, Muenke $M$. Noonan syndrome. Am Fam Physician 2014;89:37-43.

10 Kole A, Faurisson F, Ensini M, le Cam C. The voice of rare disease patients: Experiences and expectations of over 3,000 patients on rare disease patient registries in Europe. Paris: Eurordis; 2013.

11 Okkes IM, Oskam SK, Lamberts H. Van klacht naar diagnose. Bussum: Coutinho; 1998.

12 Hendriks S. Informatie voor de huisarts over amyloïdose. Soest/Utrecht: VSOP/NHG/SAN; 2016

13 Hendriks S. Informatie voor de huisarts over osteogenesis imperfecta. Soest/Utrecht: VSOP/NHG/VOI; 2010.

14 van de Putte EM, Lukkassen IMA, Russel IMB, Teeuw AH, redactie. Medisch handboek kindermishandeling. Houten: Bohn Stafleu van Loghum; 2013.

15 Heinerman BCC, van Beynum IM, Buysse, CMP. Syncope op de kinderleeftijd: niet altijd vasovagaal. Ned Tijdschr Geneeskd 2011;155:A4024.

16 Akkerhuis JM, Baars HF, Marcelis CLM, Akkerhuis KM, Wilde AAM. Congenitaal lange-QT-tijdsyndroom: oorzaak van recidiverende wegrakingen en plotse dood op jonge leeftijd. Ned Tijdschr Geneeskd 2007;151:235764.

17 de Jongh-van Hoof J, de Vries JDM, Monnens LAH. Aangeboren urethra-

\section{Jan}

Jan, 68 jaar, komt op spreekuur omdat hij sinds enige tijd snel duizelig en extreem moe is. Bovendien is hij veel zwaarder geworden de laatste tijd. $U$ kent hem als een sportieve man, die graag aan wielrennen doet. Na onderzoek stelt u vast dat Jan een zeer lage bloeddruk heeft en dat hij last heeft van hartritmestoornissen of hartfalen. $U$ verwijst hem naar de afdeling Cardiologie van het plaatselijke ziekenhuis. De cardioloog constateert dat de gangbare medicatie onvoldoende effect heeft en denkt door dit afwijkende beloop aan amyloïdose, een zeldzame stapelingsziekte. In overleg met de cardiologen in het UMC besluit ze nader histologisch onderzoek te laten doen. Inderdaad wordt in het weefselbiopt de kenmerkende amyloïdstapeling aangetroffen. Jan heeft inmiddels een ICD en het UMC verwijst hem op zijn verzoek voor een aanvullend oordeel naar het expertisecentrum.

Bij cardiale amyloïdose is uitblijvend effect van hartmedicatie een belangrijk teken. Dit zette de alerte cardioloog op het juiste spoor, maar zonder de verwijzing van de huisarts was de cardioloog niet in beeld gekomen. Als het anders gelopen was, had Jan onverwacht aan zijn hartproblemen kunnen overlijden zonder dat er een reden voor de plotselinge hartdood zou zijn gevonden. kleppen; ervaringen bij 73 kinderen. Ned Tijdschr Geneeskd 1995;139:6972.

18 Hendriks S, van Kats J. Informatie voor de huisarts over bijnierziekten. Soest/Utrecht: VSOP/NHG/NVACP; 2011.

19 Nijnuis M. Informatie voor de huisarts over fragiele-X-syndroom. Soest/ Utrecht: VSOP/NHG/Fragiele X vereniging Nederland; 2014.

20 Buntinx F, Mant D, Van den Bruel A, Donner-Banzhof N, Dinant GJ. Dealing with low-incidence serious diseases in general practice. Br J Gen Pract 2011;61:43-6.

21 Stolper CF, van de Wiel MWJ, Dinant GJ. Nascholing van huisartsen relevant voor diagnostiek? Ned Tijdschr. Geneeskd 2013;157:A6923.

22 Werkgroep Invest (Internisten voor Volwassenen met een Erfelijke Stofwisselingsziekte).Volwassenen met een erfelijke stofwisselingsziekte. Een sterk groeiende populatie met unieke problematiek. Ned Tijdschr Geneeskd. 2014;158:A7745.

23 Kahneman D, Klein G. Conditions for intuitive expertise: a failure to disagree. AmPsychol 2009;64:515-26.

24 Stolper E, Wiel van de $M$, Royen van $P$, Bokhoven van $M$, Weijden van der $T$, Dinant GJ. Gut feelings as a third track in general practitioners' diagnos tic reasoning. J Gen Intern Med 2011;26:197-203.

25 Van den Bruel A, Thompson M, Buntinx F, Mant D. Clinicians' gut feeling about serious infections in children: observational study. BMJ 2012;345:e6144.

26 Erkende expertisecentra zeldzame aandoeningen. Utrecht: NFU; 2015.

27 EUCERD recommendations on Rare Disease European Reference Networks (RD ERNS). Brussels: European Union Committee of Experts on Rare Diseases; 2013.

28 Breuning $M$. Herkennen van zeldzame syndromen is niet moeilijk. Ned Tijdschr Geneeskd 2013;157:A6085

29 Bouwman MG, Teunissen QGA, Wijburg FA, Linthorst GE. 'Doctor Google' ending the diagnostic odyssey in lysosomal storage disorders: parents using internet search engines as an effi cient diagnostic strategy in rare diseases. Arch Dis Child 2010;95:642-4.

30 Houwink EJ, Sollie AW, Numans ME, Cornel MC. Proposed roadmap to stepwise integration of genetics in family medicine and clinical research. Clin Transl Med 2013;2:5.

31 Houwink EJ, Muijtjens AM, van Teeffelen SR, Henneman L, Rethans JJ, van der Jagt LE, et al. Effectiveness of oncogenetics training on genera practitioners' consultation skills: a randomized controlled trial. Genet Med 2014;16:45-52. 